\title{
Desigualdades sociais e pobreza na Região Metropolitana de Salvador: um estudo sobre a economia popular e solidária como mecanismo de erradicação.
}

\author{
$\underline{\text { Renaildes Cintra }}{ }^{1}$; Jossel Santos ${ }^{2}$ \\ 1. Bolsista PIBIC/Fabesp, Graduando em Ciências Econômicas , Universidade Estadual de Feira de Santana, e-mail: \\ renacintra@hotmail.com \\ 2. Orientador, Departamento de Ciências Sociais Aplicadas, Universidade Estadual de Feira de Santana, e-mail: \\ josselborgessantos@gmail.com
}

PALAVRAS-CHAVE: Economia solidária, desigualdade, pobreza .

\section{INTRODUÇÃO}

Durante o período de pós-industrialização na década de 90 as economias periféricas observaram distintas mudanças nos processos de produção e no mercado de trabalho, reflexos do fenômeno da globalização e mundialização do capital. De acordo com Assis (2007) "a globalização surge como um processo de aprofundamento da integração econômica, social, político, cultural e de barateamento dos custos de transporte e comunicação entre os países do mundo no século XX”. Em se tratando de um mecanismo que visa eliminar as barreiras impostas pelas fronteiras naturais, a globalização em si, tinha o papel de interligar os países promovendo uma maior integração e comunicação entre os mesmos. No entanto, em que pese os aspectos negativos destaca-se que houve um relativo distanciamento entre as economias, alargando as disparidades socioeconômicas e exacerbando a relação centro-periféria que em sua totalidade se expressa em uma nova divisão internacional do trabalho.

Analisando os efeitos deste processo sobre a economia brasileira observou-se que no final da década de 80, o cenário conjuntural interno sofreu algumas transformações, devido, as várias mudanças ocorridas no campo macroeconômico consequência de um litigioso processo de abertura financeira e comercial do país. Segundo a reflexão dos autores Ribeiro e Oliveira (2006) sobre o Brasil destaca-se que o modelo de substituição das importações, que havia sido adotado após a II Guerra Mundial, na qual mantinha sua economia protegida, seria abandonado dando origem a um regime mais aberto do ponto vista, financeiro, comercial e de investimentos diretos. Assim com a redução da intervenção estatal em alguns setores econômicos devido à financerização da economia imposta pelo Consenso de Washington com uso do "Estado mínimo", tem- se que os segmentos que dependiam deste apoio vão sofrer fortemente com a competitividade externa e a falta de subsídios.

Ao refletir sobre esta situação no âmbito regional observa-se que a Bahia não foge a regra, descrendo as características negativas dinamizadas pela economia brasileira ao longo deste processo. Todavia, é importante ressaltar que a Bahia, já, havia iniciado o seu processo de industrialização no período fugindo do enigma baiano ${ }^{1}$. No entanto, não conseguiu reduzir os seus níveis de concentração produtivo na RMS, dado a falta de capacidade da industrial local

\footnotetext{
1 Pinto de Aguiar foi um dos primeiros teóricos a utilizar o termo enigma baiano , que caracteriza-se por ser um um fenômeno de não industrialização da Bahia até a década de 50.
} 
de gerar um efeito multiplicador sobre a produção e tão pouco aumentou o seu nível de desenvolvimento ao longo dos anos, reservando para a população local um estrema carência de renda e elevadas taxas de desemprego.

È diante deste ambiente que as ideias do cooperativismo se dinamizam na região fazendo surgir os empreendimentos de economia popular solidária que segundo os dados da Senaes nos anos de 2009 á 2013 contabilizou-se um total de 14.452 empreendimentos solidários na Bahia. Assim destaca-se que o objetivo principal do trabalho foi de verificar qual o efeito promovido pela economia popular e solidária no sentido de aumentar a inclusão socioprodutiva do trabalhador soteropolitano e na redução dos níveis de pobreza ${ }^{2}$. Sendo importante destacar que os intentos iniciais foram de analisar o processo de inserção do cooperativismo na Bahia, verificando o contexto de formação industrial e o aparecimento desta nova economia diante das defasagens apresentadas pela pouca produtividade da industrialização local no sentido de garantir renda e trabalho de forma sustentada.

\section{MATERIAL E MÉTODOS OU METODOLOGIA (ou equivalente)}

A metodologia consiste basicamente no recolhimento de dados, registros e informações adicionais que tratam dos temas ligados a Economia popular e solidária, desigualdades sociais e pobreza, na Região Metropolitana de Salvador. Assim a pesquisa caminha no primeiro momento na direção de analisar por meio de referenciais bibliográficos o processo histórico e de desenvolvimento da economia popular e solidária no Brasil e na Bahia, identificando ao longo das investigações os aspectos internos que favoreceram a difusão das ideias de cooperativismo na região. E no segundo momento destaca-se como necessidade a coleta de dados estatístico dos bancos do IBGE, Senaes, Dieese-Setre, Observatório Nacional de economia solidária e Observatório do trabalho da Bahia, para dar maior veracidade às analises elaboradas ao longo da pesquisa.

RESULTADOS E/OU DISCUSSÃO (ou Análise e discussão dos resultados)

Os resultados dinamizados pela pesquisa se estendem em uma análise teórica sobre o processo constitutivos do cooperativismo na Bahia e sua capacidade em inserir os trabalhadores no processo de produção garantindo uma melhor situação diante das contradições internas da economia baiana que mesmo conseguindo se industrializar não consegue se desenvolver socialmente, prescrevendo altos níveis de pobreza e desigualdades sociais.

Em um recorte sobre a década de 90, observa-se que o fenômeno de mundialização do capital, a globalização e a consequente restruturação produtiva vai provocar em âmbito nacional uma relativa alta nas taxas de desemprego atingindo de forma emblemática a região da Bahia. De acordo com GALLO et al (2000) " o problema do desemprego assume nova configuração tornando-se alto e prolongado. Cada vez mais utiliza-se a subcontratação e a precarização dos postos de trabalho". E a Bahia neste período apesar do relativo crescimento econômico percebe uma alta das taxas de informalidade no mercado de trabalho. Sendo que, os reflexos deste processo são a extrema pobreza da população local e para o trabalhador percebe-se um insegurança no âmbito de garantia de renda, ocupação e dos seus direitos

\footnotetext{
${ }^{2}$ Silva ( 2011) caracteriza a pobreza como uma situação de fragilidade social e privação material em que o indivíduo se encontra frente às demandas básicas de sobrevivência e cidadania.
} 
trabalhista como um todo, já que existem neste momento um certa flexibilização nas relações de trabalho ocasionados pelo enfraquecimento sindical.

Diante do cenário apresentado pela economia baiana observa-se o aparecimento de segmentos produtivos que em certa medida dialogam com o alto capital e que possuem um alto nível de inclusão socioprodutivo. São os chamados segmentos da economia popular e solidária que descrevem como característica um ambiente de produção baseado na autonomia e autogestão dos cooperados. Conforme apontam os autores Olivia; Reis e Meira ( 2009) temse que, foi somente em 2009, que a Lei Estadual do Cooperativismo na Bahia se estabeleceu, agregando os segmentos cooperativistas da agricultura familiar e outros da economia solidária, sendo que este processo foi facilitado pelo órgão de Conselho Estadual de Cooperativismo (Cecoop) que é ligado a Secretária de Trabalho, Emprego, Renda e Esporte (SETRE) ${ }^{3}$

Em uma análise dos empreendimentos de economia solidária nos territórios de identidade da Bahia no período que vai de 2009 a 2013 foi diagnosticado um total de 1.452 empreendimentos solidários, que se distribuem em sua maioria na região do Sertão Produtivo em 153 empreendimentos economia solidários( EES) e o Semiárido do Nordeste II com 122 , já para a Região Metropolitana de Salvador o número de EES foi de apenas 81 unidades produtivas.

\section{CONSIDERAÇÕES FINAIS (ou Conclusão)}

De acordo com as informações recolhidas ao longo deste trabalho pode-se observar que de uma maneira geral as dificuldades de inserção produtiva do Brasil na nova divisão internacional do trabalho, aprofundou incisivamente sua situação de precariedade no que tange ao bem-estar da sua população. Haja vista, que todas as mudanças provenientes deste contexto de mundialização do capital só ressaltaram as problemáticas internas da sua economia, prescrevendo para o trabalhador duras pena no que tange sua inclusão produtiva. Assim observa-se uma crescente onda de informalidade do trabalho nas regiões brasileira sendo que assim como no Brasil tem-se que na Bahia o resultado se materializou no aumento do nível de pobreza e desigualdades sociais, mesmo com os bons resultados dinamizados pela produção industrial destaca-se que a região não conseguiu lograr o e seu desenvolvimento, já que boa parte dos seus investimentos se concentraram na produção industrial na RMS. Esta por sua vez, observou ao longo dos anos 90 e 2000 o surgimento e crescimento das EES, que com uma nova dinâmica produtiva trouxeram como proposta para o trabalhador maior autonomia e inclusão socioprodutiva. E nos dias atuais vem crescendo o seu nível de participação sobre a economia local garantindo uma maior geração de trabalho e renda para o trabalhador soteropolitano .

\footnotetext{
3 Os dados expressos pela Bahia análise de dados de 2013, delimitam que "As cooperativas convencionais agregam, na Bahia, apenas 107.659 cooperados, portanto, 323 mil pessoas, ou seja, apenas 2,5\% da população estadual (13,5 milhões de habitantes) Tabela 1: Empreendimentos Solidários segundo Território de identidade( 2009-2013)
} 


\section{REFERÊNCIAS}

ALBAN, M. 2005. O novo enigma baiano, a questão urbana-regional e a alternativa de uma nova capital. In: ENCONTRO NACIONAL DA ANPUR, XI, 2005, Salvador, Anais.

Salvador: UFBA. Disponível: http://www.xienanpur.ufba.br/232.pdf. Acesso em 15 de março de 2015.

Assis, R. 2004. A metamorfose do trabalho pelas implicações da globalização. Cadernos de Direto, Piracicaba 7(12-13): 123-135.

OLIVIA, H.; REIS, T; MEIRA, L. 2009. Economia solidária no governo da Bahia. Ipea (Org),mercado de trabalho.

SINGER, P.; SOUZA, A. R. (Orgs.). A economia solidária no Brasil: a autogestão como resposta ao desemprego. São Paulo: Contexto, 2000.

RIBEIRO, M. ; OLIVEIRA ,L. 2006 . O Brasil no contexto das relações econômicas internacionais: Realidades e Perspectivas. 